\title{
Electrochemical Corrosion Behavior of Iron in Lithium-ion Battery Electrolyte
}

\author{
Jineun Kim ${ }^{1}$, Suhyun Lee ${ }^{1}$, Kun Woo Kim², Jungman Son ${ }^{2}$, and Junyoung Mun ${ }^{1 *}$ \\ ${ }^{1}$ Department of Energy and Chemical Engineering, Incheon National University, 119, Academy-ro, Songdo-dong, Yeonsu-gu, \\ Incheon 22012, Korea \\ ${ }^{2}$ Samsung SDI, 467, Beonyeong-ro, Seongseong-dong, Seobuk-gu, Cheonan-si, Chuncheongnam-do, 31086, Korea
}

\begin{abstract}
The element iron (Fe) is affordable and abundantly available, and thus, it finds use in a wide range of applications. As regards its application in rechargeable lithium-ion batteries (LIBs), the electrochemical reactions of Fe must be clearly understood during battery charging and discharging with the LIB electrolyte. In this study, we conducted systematic electrochemical analyses under various voltage conditions to determine the voltage at which Fe corrosion begins in general lithium salts and organic solvents used in LIBs. During cyclic voltammetry (CV) experiments, we observed a large corrosion current above $4.0 \mathrm{~V}$ (vs. $\mathrm{Li} / \mathrm{Li}^{+}$). When a constant voltage of $3.7 \mathrm{~V}$ (vs. $\mathrm{Li}^{2} / \mathrm{Li}^{+}$), was applied, the current did not increase significantly at the beginning, similar to the $\mathrm{CV}$ scenario; on the other hand, at a voltage of $3.8 \mathrm{~V}\left(\mathrm{vs} . \mathrm{Li}^{\prime} / \mathrm{Li}^{+}\right.$), the current increased rapidly. The impact of this difference was visually confirmed via scanning electron microscopy and optical microscopy. Our X-ray photoelectron spectroscopy measurements showed that at $3.7 \mathrm{~V}$, a thick organic solid electrolyte interphase (SEI) was formed atop a thin fluoride SEI, which means that at $\geq 3.8 \mathrm{~V}$, the SEI cannot prevent Fe corrosion. This result confirms that Fe corrosion begins at $3.7 \mathrm{~V}$, beyond which Fe is easily corrodible.
\end{abstract}

Keywords : Iron, Corrosion, Lithium-Ion Battery, Electrolyte, Thermodynamic Criteria

Received : 22 March 2021, Accepted : 2 April 2021

\section{Introduction}

The world is witnessing a concentrated interest and focus in the development of electric vehicles (EVs) and energy-storage systems (ESSs) in the context of addressing global environmental issues. Accordingly, research interest is shifting from small batteries used in laptops and cell phones to medium and large batteries for use in EVs and ESSs [1-4]. In this regard, lithium-ion batteries (LIBs) afford clear advantages in terms of high energy and power densities and long lifespans when compared with other existing batteries such as Ni/MH batteries. Despite these advantages, accidents related to battery safety continue to occur in EVs as well as in small devices such as cell phones and laptops. The cause of such accidents has

*E-mail address: jymun@inu.ac.kr

DOI: https://doi.org/10.33961/jecst.2021.00353

This is an open-access article distributed under the terms of the Creative Commons Attribution Non-Commercial License (http://creativecommons.org/licenses/by-nc/4.0) Attribution Non-Commercial License (http://creativecommons.org/licenses/by-nc/4.0)
which permits unrestricted non-commercial use, distribution, and reproduction in any which permits unrestricted non-commercial use, distrib
medium, provided the original work is properly cited. been attributed to the ignition of the organic solvent used as the electrolyte in lithium-ion secondary batteries [5,6]. Ignition can be caused by external shock, short circuit, pressure, and unexpectedly high temperatures. Among these factors, short circuits are caused by the metal present in the battery, and this metal plays a significant part in safety-related issues.

We note here that LIBs contain several metals $[7,8]$. Among the cell components, aluminum and copper are used as current collectors, and various other metals are also used as exterior materials. In addition to the metal components of the battery, metals are also included in the form of impurities in the manufacturing process. These metals participate in electrochemical reactions during the charging and discharging of the battery. Accordingly, the corrosion, elution, and precipitation reactions of the metal can be induced, thereby resulting in the loss of its original function or the short circuit of the battery $[9,10]$. As this situation can affect the battery safety, it becomes necessary to understand the electrochemi- 
cal mechanism of the metals in the battery.

The corrosion potential of a metal in a secondary battery must be investigated both thermodynamically and kinetically. All metals have a defined thermodynamic oxidation and reduction voltage [11]. However, in the case of the metals in a secondary battery, the tendency of the formation of a surface solid electrolyte interphase (SEI) changes because of the catalytic effect of the lithium salt, organic solvent, and metal itself, and the electrochemical reaction occurs at a voltage different from the thermodynamic voltage of the metal [12]. In general, there have been few experimental studies on the electrochemical reactions of metals in secondary batteries in the context of realizing the additional electrochemical stability of $\mathrm{Al}$ and $\mathrm{Cu}$ metals used as current collectors [2,3]. Similarly, the electrochemical behavior of $\mathrm{Fe}$ also requires to be more deeply researched. Fe offers the advantages of relative environmental friendliness, abundant availability, and low cost, and thus, there have been continued efforts to use Fe in batteries, for e.g., in $\mathrm{Ni} / \mathrm{Fe}$ batteries, $\mathrm{Fe}$ redox flow batteries, and $\mathrm{LiFePO}_{4}$ cathode materials [4,5].

Meanwhile, as regards LIBs, coin and cylindrical cells in particular are coated by an outer layer of stainless steel for safety reasons. The peeling off of this outer film causes the additional corrosion of $\mathrm{Fe}$. In addition, $\mathrm{Fe}$ is included as an impurity in the manufacturing process of active battery materials and participates in electrochemical reactions, and thus, it becomes necessary to study the electrochemical behavior of $\mathrm{Fe}$ in secondary batteries.

However, the electrochemical behavior of Fe with LIB electrolytes has not been investigated despite its practical necessity. Therefore, in this study, we examine the corrosion behavior of $\mathrm{Fe}$ foil induced by a voltage applied to the commonly used $1 \mathrm{M} \mathrm{LiPF}_{6}$ lithium salt and ethylene carbonate/diethyl carbonate (EC/DEC) organic solvent. We analyze the SEI composition according to the voltage range, and we discuss the corrosion behavior of Fe.

\section{Experimental}

\subsection{Electrode and cell fabrication}

In this study, Fe foil was used as an electrode to investigate its electrochemical behavior in a battery. We used a Fe foil with a thickness of $50 \mu \mathrm{m}$ and purity of $99.9 \%$ (R\&D Korea). First, to control the area of the Fe foil, a hole with a diameter of $14 \mathrm{~mm}$ was punched in the foil, and subsequently, the size of the exposed Fe foil was controlled to a diameter of $12 \mathrm{~mm}$ by affixing an imide tape with a $12 \mathrm{~mm}$-diameter hole. The prepared $\mathrm{Fe}$ foil assembly was dried for $10 \mathrm{~h}$ under vacuum at $120^{\circ} \mathrm{C}$ to remove moisture.

Experimental cells were manufactured in a glove box under an argon atmosphere, wherein oxygen and moisture were controlled [12]. Fe foil was used as the working electrode, and a Li metal disc with a diameter of $14 \mathrm{~mm}$ was used as the reference and counter electrodes. Polypropylene (PP) was used as the separator. The electrolyte was prepared with a solution in which $1 \mathrm{M}$ lithium hexafluorophosphate $\left(\mathrm{LiPF}_{6}\right)$ salt was mixed in a 1:1 volume ratio of ethylene carbonate (EC) and ethyl methyl carbonate (EMC), after which the cell was finally constructed. Subsequently, 2032-type half cells were prepared.

\subsection{Electrochemical evaluation}

The electrochemical performance of the coin cell was evaluated using a WBCS3000 system (WonAtech, Korea). Charging and discharging were performed in a chamber at $25^{\circ} \mathrm{C}$. For each coin cell, the electrode was subjected to a $10 \mathrm{~min}$ rest. In the case of cyclic voltammetry (CV) experiments, the starting voltage was set to $3.0 \mathrm{~V}$, and the upper-limit voltage was varied as $3.5,3.7,4.0$, and $4.2 \mathrm{~V}$ (vs. $\mathrm{Li} / \mathrm{Li}^{+}$) in that order. The cell was charged and discharged at a constant rate of $10 \mathrm{mV} / \mathrm{s}$ to reach each voltage. Moreover, in the constant-voltage experiments, the starting voltage was set to $3.0 \mathrm{~V}$, and the upper-limit voltage was varied as 3.3, 3.5, 3,7, 3.8, 4.0, and $4.2 \mathrm{~V}$ (vs. Li/ $\left.\mathrm{Li}^{+}\right)$in that order. Charging was carried out at a rate of $10 \mathrm{mV} / \mathrm{s}$, similar to the $\mathrm{CV}$ experiments, and the constant-voltage retention time was set as $24 \mathrm{~h}$ after reaching each voltage.

The electrodes used for scanning electron microscopy (SEM), optical microscopy, and X-ray photoelectron spectroscopy (XPS) measurements were obtained by disassembling the battery after the constant-voltage tests. After these tests, the Fe-foil surface was observed using the JSM-7001F fieldemission SEM. The DSX1000 (Olympus) optical microscope was used to acquire $3 \mathrm{D}$ views of the corroded region. After the constant-voltage test, SEI analysis of the electrode surface was performed using a scanning photoelectron spectroscopic analyzer (XPS, PHI 5000 Versa Probe II). 
Linear-sweep thermammetry (LSTA) evaluations were performed using the WonATech WBCS3000 charger and discharger. The upper-limit voltage was set to 3.3 and $3.5 \mathrm{~V}$, and each cell was examined after raising the voltage from the starting voltage of $3.0 \mathrm{~V}$ to each upper-limit voltage at a rate of $10 \mathrm{mV} / \mathrm{s}$, as in the constant-voltage experiment. The temperature was set to vary from $25^{\circ} \mathrm{C}$ at room temperature to $120^{\circ} \mathrm{C}$ at the upper limit and raised at a rate of $0.1^{\circ} \mathrm{C} /$ $\min$.

\section{Results and Discussion}

First, to understand the corrosion behavior, we examine the $\mathrm{CV}$ results of the lithium/iron foil halfcell shown in Fig. 1. For the evaluation of the influence of iron under various voltage conditions for the positive electrode of the rechargeable batteries, the upper-limit voltage was varied as 3.5, 3.7, 4.0, and 4.2 V vs. $\mathrm{Li} / \mathrm{Li}^{+}$in that order. As shown in Fig. 1a, the current slightly increases as the voltage increases from the initial open-circuit voltage at $3.5 \mathrm{~V}$. However, the low current reflecting the corrosion of $\mathrm{Fe}$ is not significant, that is, there is no corrosion. In particular, the peak current for the $1^{\text {st }}$ and $10^{\text {th }}$ cycles is $<4$ $\mu \mathrm{A}$. The nearly constant peak current indicates that the electrochemical corrosion current is negligible. At $3.7 \mathrm{~V}$, the observed peak current values of 5.47 and $5.97 \mu \mathrm{A}$ for the $1^{\text {st }}$ and $10^{\text {th }}$ cycles, respectively, can similarly be considered to be stabilized currents without the occurrence of corrosion. At $4.0 \mathrm{~V}$ (Fig. 1c), the current behavior is significantly different from those shown in Figs. 1a and b. During the $1^{\text {st }}$ cycle, the current rapidly increases after $4.0 \mathrm{~V}$, and the subsequent current during the reverse (negative) scan is higher than that for the initial positive scan. This current further increases instead of decreasing as the number of cycles increases, the observed peak current values of 89.7 and $350 \mu \mathrm{A}$ for the $1^{\text {st }}$ and $10^{\text {th }}$ cycle respectively. This increasing current behavior can also observed in Fig. 1d for the cut-off potential of $4.2 \mathrm{~V}$. Again, the current during the initial scan exhibits a higher value than during the reverse negative scan. The peak current also increases as cycling proceeds, exhibiting values of 96.0 and $349.4 \mu \mathrm{A}$ for the $1^{\text {st }}$ and $10^{\text {th }}$ cycle, respectively. Here, we note that
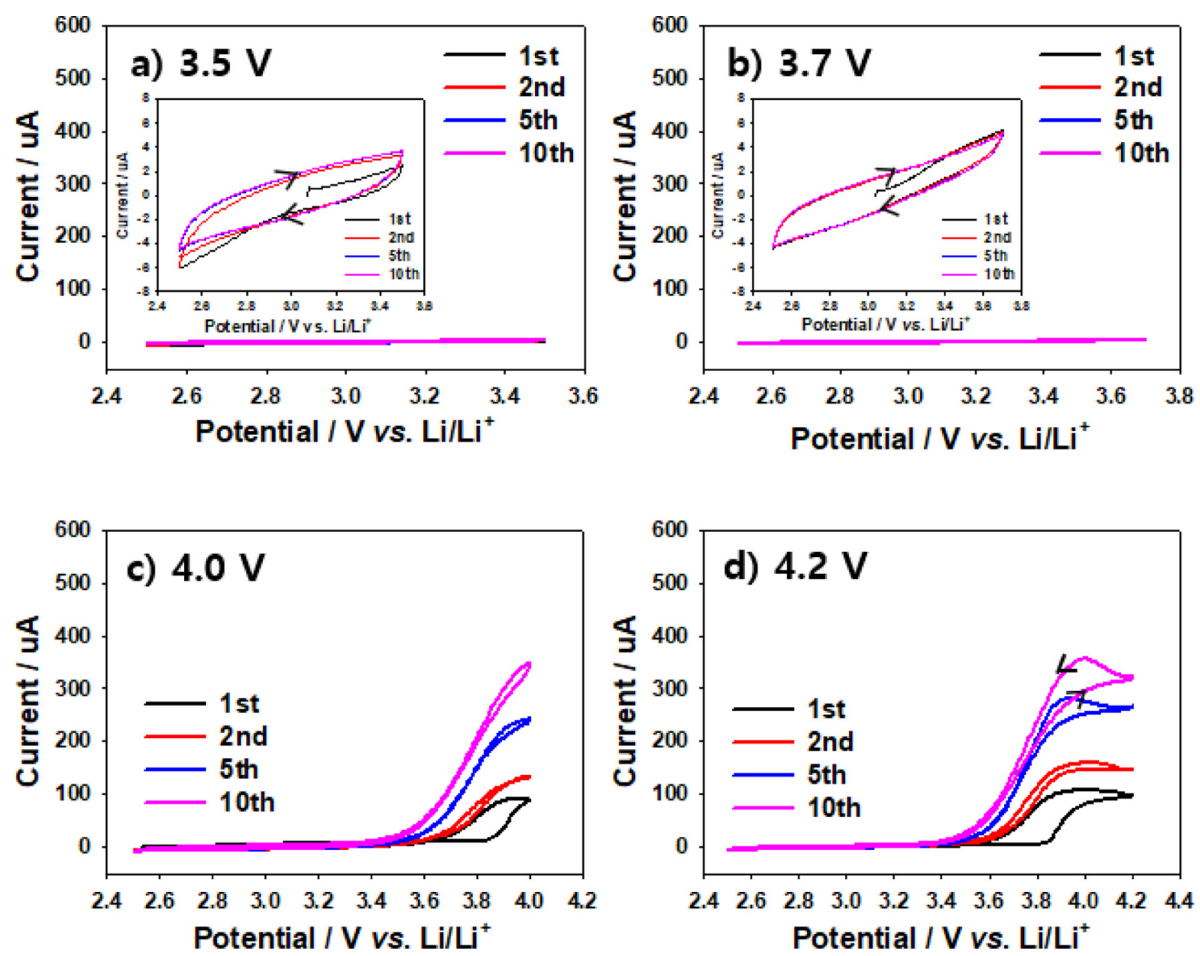

Fig. 1. Cyclic voltammetry $(\mathrm{CV})$ results of Fe foil subjected to various voltage conditions over $10 \mathrm{cycles}$ with $1 \mathrm{M}$ LiPF $/$ EC:EMC (1:1 vol\%) electrolyte. 
a)

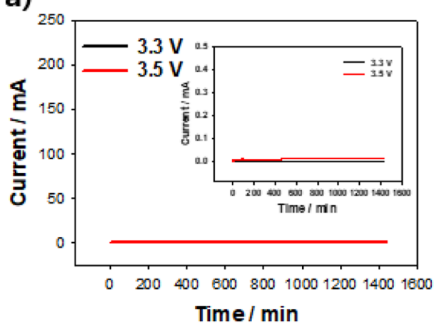

b)

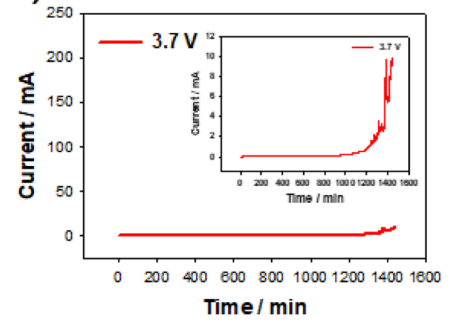

c)

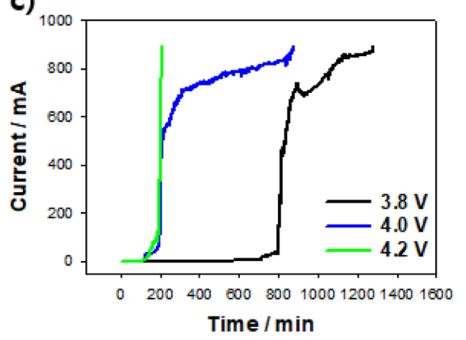

Fig. 2. Constant-voltage current measurements of $\mathrm{Fe}$ foil under various voltage conditions over $24 \mathrm{~h}$ with $1 \mathrm{M} \mathrm{LiPF}_{6} /$ EC:EMC (1:1 vol\%) electrolyte.

surface passivation by the SEI from the electrolyte leads to a decrease in current as cycling proceeds. Thus, this abnormal current behavior, that is, the high current during the reverse scan and the subsequent cycles, represents the corrosion behavior of the $\mathrm{Fe}$ foil. The initial native surface layers, which are oxides or possibly passivation layers, are initially highly resistive to iron corrosion, even at potentials higher than the equilibrium potential of $\mathrm{Fe} / \mathrm{Fe}^{2+}$. At potentials higher than $4.0 \mathrm{~V}$, the passivation layer is no longer effective in hindering the corrosion, and iron dissolution is thought to have begun. This corrosive layer accumulates on the fresh surface of the metal, which does not have native surface passivation. This fresh metal further accelerates the generation of additional corrosion current, as shown in Figs. $1 \mathrm{c}$ and $\mathrm{d}$ [4]. We note that the corrosion of Fe foil begins at $4.0 \mathrm{~V}$ or higher in $1 \mathrm{M} \mathrm{LiPF}_{6}$.

To understand the electrochemical behavior under practical LIB-operation conditions, we performed galvanostatic potentiometry for $24 \mathrm{~h}$ keeping mind that the CV conditions slightly differ from the actual LIB conditions (wherein there is no sweep-potential application). From Fig. 2a, we note that the current is highly stabilized under at 0.055 and $14.4 \mu \mathrm{A}$ under the application of 3.3 and $3.5 \mathrm{~V}$, respectively. However, the current under the application of $3.7 \mathrm{~V}$ (Fig. 2b) exhibits an increasing trend after $1000 \mathrm{~min}$. This result indicates that the $\mathrm{Fe}$ corrosion is initially blocked, and corrosion begins after $1000 \mathrm{~min}$. This electrochemical behavior is different from that corresponding to the CV curves shown in Fig. 1b. This difference indicates that the constant-potential method is more appropriate for determining the corrosion behavior and estimating the electrochemical corrosion current after long storage times, similar to actual LIB conditions. In the galvanostatic amperom- etry measurements under potentials of $3.8,4.0$, and $4.2 \mathrm{~V}$ (Fig. 2c), the corrosion current significantly increases. The time at which Fe corrosion occurs also decreases as the potential increases. At the current of $200 \mathrm{~mA}$, the half-cells exhibit operation times of 807 and $200 \mathrm{~min}$ for 3.8 and $4.2 \mathrm{~V}$, respectively. This result means that a certain amount of Fe will corrode faster at 4.0 and $4.2 \mathrm{~V}$ than at $3.8 \mathrm{~V}$. In this manner, we confirmed that the corrosion of the Fe foil is smooth at $>3.8 \mathrm{~V}$, and that the elution accelerates as the voltage increases.

To visually examine the correlation between the current and corrosion for each voltage, we examined the surface of the Fe foil electrode using SEM (Fig. 3 ). For the SEM analyses, we used an Fe foil obtained by disassembling a cell subjected to constant-voltage testing for $24 \mathrm{~h}$. In the case of the bare Fe foil (Fig. 3a), we find that the foil surface is smooth without any signs of corrosion. At $3.5 \mathrm{~V}$ (Fig. $3 \mathrm{~b}$ ), when compared with bare Fe foil, weak but insignificant scratches can be observed. At $3.7 \mathrm{~V}$ (Fig. 3c), we find that the Fe foil is subjected to pitting corrosion. However, we also note that corrosion does not occur across the entire surface. This behavior is consistent with the increasing current trend in the constant-voltage experiments. In the range of 3.8 to $4.2 \mathrm{~V}$ (Figs. 3d-f), we observe that corrosion occurs across almost the entire surface, which is also consistent with the flow of a large corrosion current, unlike at $\leq 3.7 \mathrm{~V}$ in the constant-voltage tests. Corrosion can be observed to occur from $3.7 \mathrm{~V}$ onward and accelerate with further potential increase.

Fig. 4 shows the high-magnification SEM images acquired to determine the tendency of surface SEI formation at each voltage. First, we note that the cycled Fe exhibits an irregular structure across the entire surface region when compared with the bare 

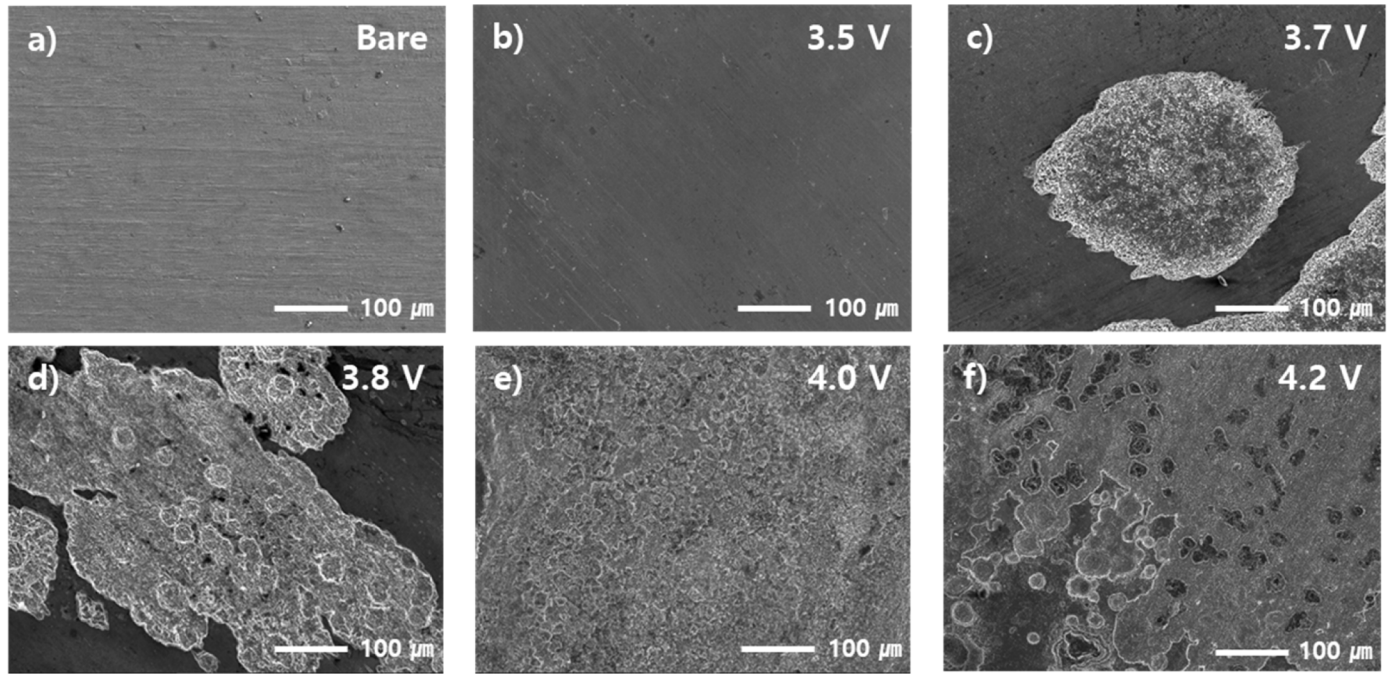

Fig. 3. SEM images of cycled cells under a constant voltage for $24 \mathrm{~h}$ under various voltage conditions.
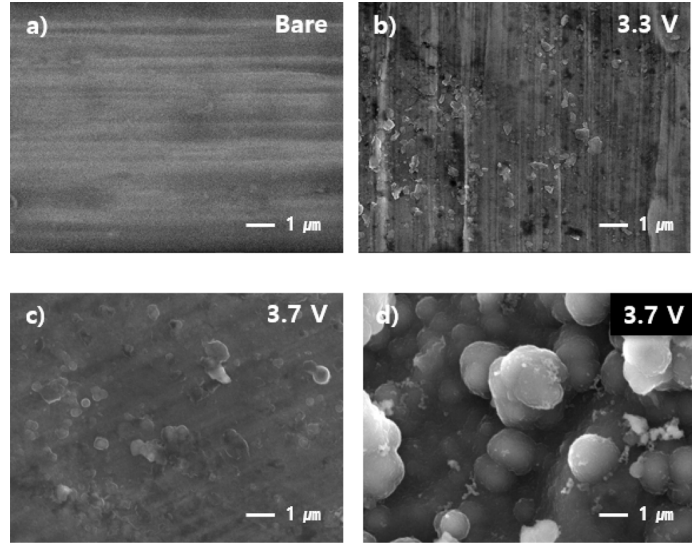

Fig. 4. Magnified SEM images of bare and cycled cells after constant-voltage ( 3.3 and $3.7 \mathrm{~V}$ ) application for $24 \mathrm{~h}$.

Fe foil (Fig. 4a) because of the formation of a lowconductivity SEI surface composed of organic and inorganic materials. Additionally, at 3.3 V (Fig. 4b), we note that an uneven film is formed on the surface when compared with the bare Fe foil. This result indicates the possibility that the SEI film deposited from the electrolyte hinders the electrochemical corrosion of iron even at potentials higher than the equilibrium potential. Consequently, we note that in the case of $\mathrm{Fe}$, the SEI is formed at values below $3.3 \mathrm{~V}$ in the general electrolyte. In addition, from Fig. 4c, we note that the SEI is formed on the surface of the electrode at the point where corrosion started to occur, although no corrosion is observed at $3.3 \mathrm{~V}$ in this portion of the foil. From Fig. 4d, we observe that the SEI is still present in the part where the corrosion occurred at $3.7 \mathrm{~V}$. These results indicate that despite SEI presence, Fe corrosion is initiated in a specific voltage range greater than that corresponding to the SEI resistance, that is, $3.7 \mathrm{~V}$.

To examine the corrosion pattern of the Fe foil, we acquired optical microscopy and 3D-mapped images; these results are shown in Fig. 5. In this case, we used an electrode obtained after a $24 \mathrm{~h}$ constant-voltage test during which Fe corrosion was initiated. From the 2D image shown in Fig. 5a, we note that the corrosion in terms of shape and size is similar to that observed in the SEM images. From the converted 3D images (Figs. 5b and c), we note that the corrosion is significant around the central region, thus resulting in a pitted shape. This result indicates that the observed corrosion does not generate a thin or uniform pattern; the corrosion is deep at the center and begins to spreads outward, and the underlying mechanism is similar to that of pitting corrosion. In the case of the $\mathrm{Fe}$ foil, an SEI is formed in the low-voltage regime (3.3 V), and therefore, corrosion does not occur even in the thermodynamic voltage range.

After performing constant-voltage experiments at 3.7 V, we conducted XPS analysis to determine the composition of the Fe-foil SEI obtained after disassembling the coin cell. From previous experiments, we confirmed that the corrosion-related current 

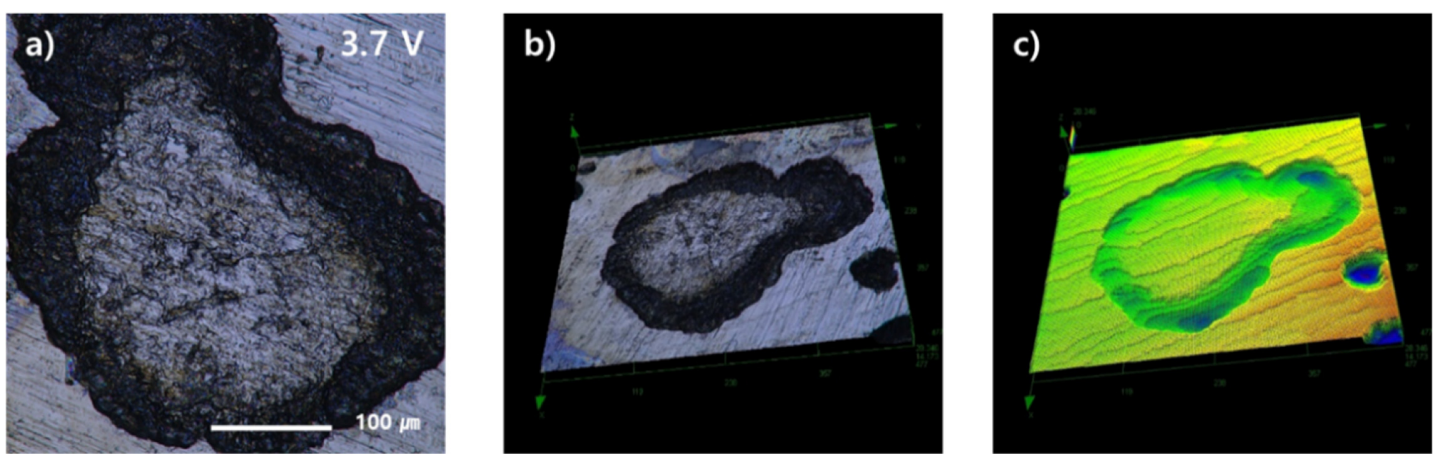

Fig. 5. Optical microscope images of cycled cells after being subjected to a constant voltage of $3.7 \mathrm{~V}$ for $24 \mathrm{~h}$.

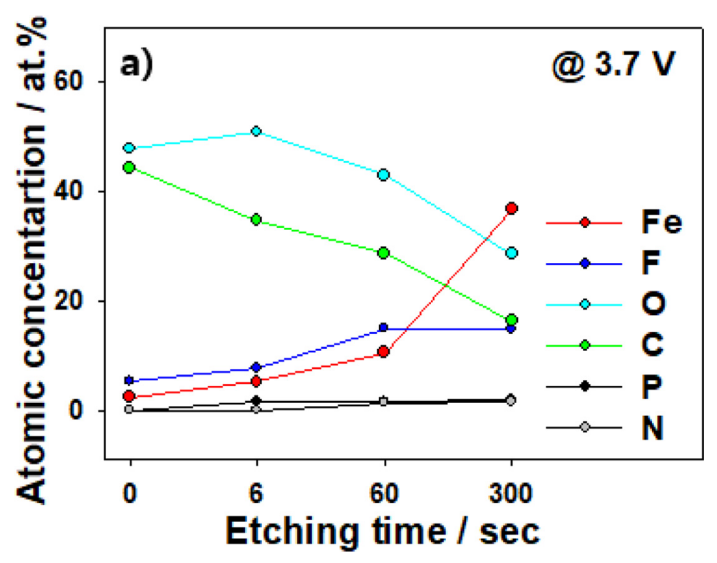

Fig. 6. Surface atomic concentrations obtained via XPS measurements for various etching times after constantvoltage application $(3.7 \mathrm{~V})$.

behavior of the Fe foil before and after the application of $3.7 \mathrm{~V}$ at room temperature was different; these results are shown in Fig. 6. First, we note from the XPS results that the SEI as observed by SEM still exists at $3.7 \mathrm{~V}$. At etching time $=0 \mathrm{~s}$, the atomic concentrations of $\mathrm{O}$ and $\mathrm{C}$ on the surface are $44.3 \%$ and $47.9 \%$, respectively, which confirms the formation of an organic SEI. Next, we increased the etching time to $300 \mathrm{~s}$ and subsequently analyzed the composition of each SEI layer. After $300 \mathrm{~s}$ of etching, the $\mathrm{C}$ and $\mathrm{O}$ concentrations decrease to $16.3 \%$ and $28.6 \%$, respectively, whereas $\mathrm{Fe}$ and $\mathrm{F}$ increase from $2.4 \%$ and $5.3 \%$ to $36.8 \%$ and $14.9 \%$, respectively. This result confirms that a fluoride-based film is formed on the lower side of the SEI, different from the top-surface composition. These results again confirm that the SEI exists even at $3.7 \mathrm{~V}$ when corrosion starts and further

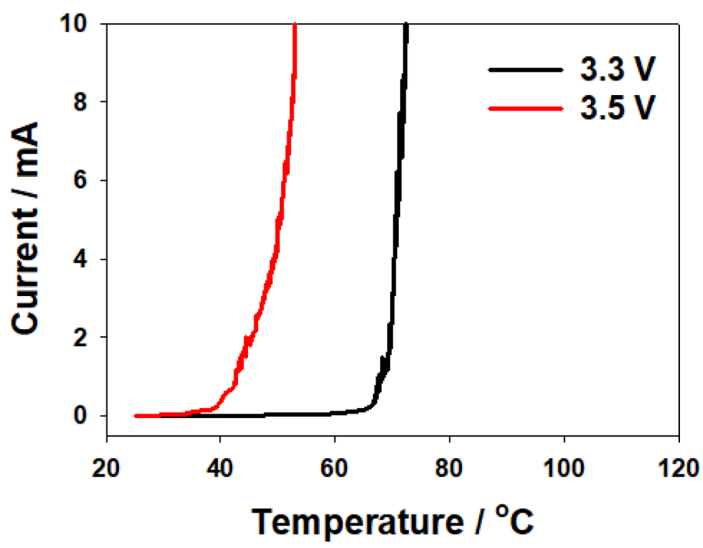

Fig. 7. Results of linear-sweep thermammetry experiments.

that the corrosion is a result of applying a voltage higher than the SEI resistance, and not SEI decomposition.

To determine whether corrosion occurs if the kinematic criteria are satisfied in the low-voltage regime, we increased the temperature at 3.3 and $3.5 \mathrm{~V}$ (at which values no corrosion occurred in our constantvoltage tests) and studied the flow of corrosionrelated current. We conducted an LSTA experiment, whose results are shown in Fig. 7. As the temperature increases, at 3.3 and $3.5 \mathrm{~V}$, the current increases dramatically above a certain temperature in each case. When the current value at which corrosion starts is taken as the standard of $10 \mathrm{~mA}$ (the maximum current value corresponding to the constant voltage of $3.7 \mathrm{~V}$ ), the temperatures corresponding to $10 \mathrm{~mA}$ are measured at 3.3 and $3.5 \mathrm{~V}$ to be $72.9^{\circ} \mathrm{C}$ and $53.3^{\circ} \mathrm{C}$, respectively. We find that corrosion is initiated at a higher temperature at lower voltages: corrosion is 
observed to occur at 3.3 and $3.5 \mathrm{~V}$ unlike in the previous experiments, which confirms that corrosion occurs when the thermodynamic conditions are satisfied, that is, when the temperature increases.

\section{Conclusions}

In this study, we investigated the corrosion behavior of Fe metal in an LIB electrolyte composed of 1.0 $\mathrm{M} \mathrm{LiPF}{ }_{6}$ in EC:EMC solvent (1:1 volume ratio). First, cyclic voltammetry and constant-voltage experiments were conducted to determine the onset voltage at which corrosion began. In the CV experiments, the corrosion-related current of $\mathrm{Fe}$ foil was not significantly observed below $3.7 \mathrm{~V}$ vs. $\mathrm{Li} / \mathrm{Li}^{+}$; however, in the constant-voltage experiments that are similar to the actual battery operation conditions, a corrosion current was observed even at 3.7 V. We used to SEM and optical microscope observations to confirm that corrosion was initiated at $3.7 \mathrm{~V}$, and we determined that the corrosion was of the pitting type based on 3D mapping images. We also determined that an SEI was maintained even after corrosion. Our findings indicate that corrosion occurs owing to high polarization, which enables electron transfer without SEI decomposition. In addition, we observed that corrosion occurred at lower potentials as the temperature was increased in the voltage range in which roomtemperature corrosion did not occur. Thus, we conclude that the thermodynamic factors underlying metal corrosion in lithium secondary batteries must also be considered for practical application.

\section{Acknowledgements}

This research was supported by the Incheon National University Grant in 2020.

\section{References}

[1] L. Lu, X. Han, J. Li, J. Hua and M. Ouyang, J. Power Sources., 2013, 226, 272-288.

[2] S. Peterson, J. Apt and J. Whitacre, J. Power Sources., 2010, 195(8), 2385-2392.

[3] D. Stroe, V. Knap, M. Swierczynski, A. Stroe and R. Teodorescu, IEEE Trans. Ind. Appl., 2017, 53(1), 430438.

[4] A. Barre, B. Deguilhem, S. Grolleau, M. Gerard, F. Suard and D. Riu, J. Power Sources., 2013, 241, 680689.

[5] Q. Wang, P. Ping, W. Zhao, G. Chu, J. Sun and C. Chen, J. Power Sources., 2012, 208, 210-224.

[6] M. Henriksen, K. Vaagsaether, J. Lundeberg, S. Forseth and D. Bjerketvedt, J. Hazard. Mater, 2019, 371, 1-7.

[7] A. Kayyar, J. Huang, M. Samiee and J. Luo, Journal of Visualized Experiments., 2012, 66, 4104.

[8] Y. Liang, C. Zhao, H. Yuan, Y. Chen, W. Zhang, J. Huang, D. Yu, Y. Liu, M. Titirici, Y. Chueh, H. Yu and Q. Zhang, InfoMat., 2019, 1(1), 6-32.

[9] W. Xu, J. Wang, F. Ding, X. Chen, E. Nasybulin, Y. Zhang and J. Zhang, Energy Environ. Sci., 2014, 7(2), 513-537.

[10] W. Kicinski and S. Dyjak, Carbon., 2020, 168, 748-845.

[11] S. Bratsch, J Phys Chem Ref Data., 1989, 18(1), 1-21.

[12] S. Solchenbach, G. Hong, A. Freiberg, R. Jung and H. Gasteiger, J. Electrochem. Soc., 2018, 165(4), A3304.

[13] T. Ma, G. Xu, Y. Li, L. Wang, X. He, J. Zheng, J. Liu, M. Engelhard, P. Zapol, L. Curtiss, J. Jorne, K. Amine and Z. Chen, J. Phys. Chem., 2017, 8(5), 1072-1077.

[14] X. Zhang, A. Wang, R. Lv and J. Luo, Energy Stor. Mater., 2019, 18, 199-204.

[15] C. Guan, W. Zhao, Y. Hu, Q. Ke, X. Li, H. Zhang and J. Wang, Adv. Energy Mater, 2016, 6(20), 1601034.

[16] Y. Wen, H. Zhang, P. Qian, H. Zhou, P. Zhao, B. Yi and Y. Yang, Electrochimica Acta, 2006, 51(18), 3769-3775.

[17] W. Zhang, J. Power Sources., 2011, 196(6), 2962-2970.

[18] D. Aurbach, B. Markovsky, A. Shenchter, Y. Eli and H. Cohen, J. Electrochem. Soc., 1996, 143(12), 3809. 